\title{
Nigeria research reactor-1: Vertical detector efficiency calibration using conventional and semi-empirical approach for large samples NAA implementation
}

\author{
Abubakar Aliyu Umar a, b, ${ }^{\star}$, Khaidzir Hamzah c, Muneer Aziz Mohammed Saleh c, Sibkrishna \\ Ghoshal $^{d}$, Muhammad Muhammad Rawi ${ }^{e}$, Sadiq Umar ${ }^{f}$, Jonah Sunday Adesoloye ${ }^{g}$, Jatau Bashir \\ Danladi $c, f$
}

${ }^{a}$ Faculty of Engineering, under Generic Program, Universiti Teknologi Malaysia, 81310 UTM Johor Bahru, Johor, Malaysia

${ }^{b}$ Institute of Education, Physics Unit, Ahmadu Bello University Zaria, Nigeria

${ }^{c}$ Department of Energy, Faculty of Chemical Engineering, Universiti Teknologi Malaysia, 81310 UTM Johor Bahru, Johor, Malaysia

${ }^{d}$ Department of physics, Faculty of science, Universiti Teknologi Malaysia, 81310 UTM Johor Bahru, Johor, Malaysia

e Agency Nuclear Malaysia, Pusat Teknologi Reaktor Kuala Lumpur, Malaysia

${ }^{f}$ Department of Physics, Faculty of Physical sciences, Ahmadu Bello Universiti Zaria, Nigeria

${ }^{g}$ Centre for Energy Research and Training, Ahmadu Bello Universiti Zaria, Nigeria

*Corresponding author: auabubakarphysics@gmail.com

\section{Article history}

Received 4 February 2019

Revised 4 June 2018

Accepted 14 August 2018

Published Online 23 April 2019

\begin{abstract}
Detector efficiency calibration is mandatory for accurate measurement of induced activity in irradiated samples and for safe operation of the reactor with minimal uncertainty. This paper reported the efficiency calibration of vertically dlpstick High Purity Germanium detector, installed at the Centre for Energy Research and Training, Ahmadu Bello University Zaria for the purpose of large sample Neutron Activation Analysis (NAA) using Nigeria research reactor-1 (NIRR-1). The performance of the detector was evaluated for the radioisotope activity measurements during the reactor operation for large samples neutron activation analysis. The detector performance in terms of radioisotopes detection ability was inspected using the standard conventional and semi-empirical approaches. The full energy peak efficiencies were determined at the corresponding energies for three different geometries (source to detector distance of 1,5 and $10 \mathrm{~cm}$ ). The semi-empirical approach produced better and precise results that logically rhymed with theory than the traditional approach. Besides that, a consistency in the nature of the graphs and values were evidenced. The determined efficiencies and their corresponding energies revealed encouraging outcome and ensured the successful NAA for large samples of different material compositions.
\end{abstract}

Keywords: NIRR-1, HPGe detector, efficiency calibration, conventional approach, semi-empirical approach, LSNAA.

(C) 2019 Penerbit UTM Press. All rights reserved

\section{INTRODUCTION}

Nigeria Research Reactor -1 is a low power miniature neutron source reactor (MNSR) of $31 \mathrm{~kW}$ power and reactivity of $3.77 \mathrm{mk}$, which is commissioned on $3^{\text {rd }}$ February 2004 . This simple reactor uses a horizontal dipstick high purity germanium (HPGe) detector for four years, which is suddenly replaced by a vertical dipstick one. To achieve the experimental reliability and precision, the efficiency calibration of the new HpGe detector becomes necessary (Jonah et al., 2007; Hamidatou et al., 2015).

The detection sensitivity in $\gamma$-ray spectrometry can be improved using the standard source samples. A reliable radionuclide activity measurement can only be achieved if there is clear knowledge of counting conditions of the detector's absolute peak efficiency. This becomes a complex problem when more than one geometry are involved in the count rate measurements, depending on the source characterization or source-detector configuration. This approach requires two different experimental inputs. First, the radioactive sources emitting $\gamma$-rays cascade input covering the energy range of interest. Second, the sources emitting isolated $\gamma$-rays for semi-empirical approach to provide some coincidence points with which the corrections can be notified (Greenberg et al., 2011; Hamidatou, et al., 2013). Consequently, it is essential to determine the efficiency in each set of standard sources for different geometries. Besides that, it is important to determine the efficiencies at several energies of the $\gamma$-ray spectrum to achieve the precise detector efficiency calibration. In this spirit, the $\gamma$-rays emitting sources was used in this research that including Americium $\left({ }^{241} \mathrm{Am}\right)$, Radium $\left({ }^{226} \mathrm{Ra}\right)$ Europium $\left({ }^{152} \mathrm{Eu}\right)$, Cesium $\left({ }^{137} \mathrm{Cs}\right)$, Cobalt $\left({ }^{60} \mathrm{Co}\right)$, Manganese $\left({ }^{55} \mathrm{Mn}\right)$ and Sodium $\left({ }^{22} \mathrm{Na}\right)$ (Khandaker 2011).

Efficiency calibration as a function of energy provides the efficiency value at any energy within a given range, with the energy range covered is being depended on the application. Therefore, the energy of any natural $\gamma$-ray source emitters can easily be determined if its efficiency is well known and fell within the range of the specified energies for the three regions explained below. Present research covered the extended energy range to detect several artificial radionuclides that were radiologically importance. Furthermore, the activity of some naturally occurring radionuclides was previously determined (Sadiq 2010; Jonah et al., 2005). 
Present work used conventional and semi-empirical approaches to ensure the correct data obtained from neutron NAA in the NIRR-1, which are the standard requirements of world nuclear regulatory authorities. Thus, HPGe detector was carefully calibrated using standard $\gamma$-ray sources to determine the detector efficiency. The expected efficiencies must fall within the operational range and fitted gamma energies regardless of the position of the $\gamma$ sources or sourceto-detector geometry, (Abubakar et al., 2017). The results obtained using the conventional and semi-empirical approaches were consistent at any desired energy and source-to-detector distances and found to be better than earlier findings (Jonah et al., 2005; Alghem et al., 2006; Musa et al., 2014).

\section{EXPERIMENTAL}

\section{Materials and Methods}

\section{HPGe detector efficiency calibrations via conventional approach}

The standard $\gamma$-ray sources were measured three times in different geometries (far and near) for varying energy ranges. The source to detector distances of $1 \mathrm{~cm}$ and $10 \mathrm{~cm}$ were considered close and far geometry respectively. A round plastic sample source holder fabricated in Centre for Energy Research and Training (CERT) workshop laboratory was used for radiation detection where the standard sources were placed at the centre of the holder. The holder has three geometry steps in the design. The $\gamma$-ray sources such as Americium $\left({ }^{241} \mathrm{Am}\right)$, Radium $\left({ }^{226} \mathrm{Ra}\right)$ Europium $\left({ }^{152} \mathrm{Eu}\right)$, Cesium $\left({ }^{137} \mathrm{Cs}\right)$, Cobalt $\left({ }^{60} \mathrm{Co}\right)$, Manganese $\left({ }^{55} \mathrm{Mn}\right)$ and Sodium $\left({ }^{22} \mathrm{Na}\right)$ were placed on the holder (for the three geometries 1,5 and $10 \mathrm{~cm}$ ) and measured for 300,600 and 900 seconds. The net areas for all the peak energy spectra were observed on the $\gamma$-ray spectrometer and plotted (Figure 1 to 3 ). The full energy peak (FEP) efficiencies were calculated and the efficiency versus energy response were determined (Jonah et al., 2007; Jonah et al., 2009; Abubakar et al., 2017).

\section{HPGe detector efficiency calibrations via semi-empirical approach}

In this approach, the coincidence factors should be corrected with the experimental or conventional efficiencies for $\gamma$-ray emitting sources. The calibration curves might fall within the energy range of 50 $\mathrm{KeV}$ to $4 \mathrm{MeV}$. Three energy regions were considered as follows: Region I: 50 to $90 \mathrm{KeV}$; Region 2: 90 - $200 \mathrm{KeV}$. Region 3: above 200 $\mathrm{KeV}$. The efficiencies in region I largely depended on three major factors including the active surface area of the HPGe detector (co-axial vertical dipstick), the attenuation on its aluminum end-cap and the dead layer of either p-type or n-type germanium detectors. The intrinsic efficiency was the most important factor. The target or missing efficiency could be determined in terms of ideal efficiency that might be used to achieve the complete characteristic curve with average energy of $60 \mathrm{KeV}$. The average energy in the mass attenuation coefficient $(\boldsymbol{\mu})$ data was used, which corresponded to ${ }^{241} \mathrm{Am}$ standard $\gamma$ ray source.

In region II, a well calibrated efficiency curve could be obtained by providing two energy boundaries points, which were $90 \mathrm{KeV}$ and 200 $\mathrm{KeV}$. The value of detector's volume was calculated in terms of length $(6.66 \mathrm{~cm})$ and diameter $(5.71 \mathrm{~cm})$. For region with energy above 200 $\mathrm{KeV}$, the efficiency calibration curve was a linear function of the logarithmic energies, defined by a polynomial expression. The calibration curve in the energy range of $200 \mathrm{KeV}$ to $4 \mathrm{MeV}$ with two widely spaced efficiency points was used and obtained for ${ }^{137} \mathrm{Cs}(661$ $\mathrm{KeV}$ ) and ${ }^{60} \mathrm{Co}(1332 \mathrm{KeV})$ (Akaho and Nyarko 2002, Jonah et al., 2009, Abubakar et al., 2017).

\section{HPGe Detector}

It is a calibrated semiconductor detector based on photo-radiation verifier with an extensive range of energies. We used Oak Ridge Technical Enterprises Corp., (ORTEC) HPGe (P-type) detector of high resistivity that cryogenically manufactured at low temperature range, having similar impurity concentration for lithium elimination. For the best count, the resistivity of the detector must be proportional to the thickness of the depletion layer. Moreover, HPGe detector was advantageous over other detectors, owing to its high resolution, conductivity, atomic number, high production of electron hole pair at low ionizing energy, low impurity concentration and easy in operation. Particularly, the decay count by vertical dipstick HPGe detector was superior to its horizontal counterpart. On top, the pair production process was more predominant and pronounced, where the shape and resolute net area of the full energy peak could easily be detected (Sadiq et al., 2010; Abubakar et al., 2017).

\section{Energy calibration of the detector}

All the measurements of reactor were absolutely relied on the prompt energy calibration. It was determined from the peak areas of the energy spectra of the standard $\gamma$-ray emitting sources. The first set of sources was used for the background count, while the later was utilized for the energy calibrations as well as peak area determination. The spectra were determined using the Multchannel Analyser Emulation Software (MAESTRO-32), which visualized the entire gamma spectroscopy in the NAA labouratory counting room. Therefore, the data obtained from the aforementioned spectra was further analyzed for energy calibration (Jonah et al., 2009). The precise energy and efficiency calibration were performed using multi- $\gamma$-ray standard sources (De Corte et al., 2001; Vermaercke et al., 2006).

\section{Efficiency calibration of the detector}

The efficiency of the vertical dipstick HPGe ORTEC coaxial detector was computed using the original database and edit, the certified sources information and the dimension of the detector. The calibrated efficiency was used to establish the relationship between the probability of the detector recording in the full energy peak and the peak energy. The present activities of the radionuclides were calculated using the peak areas and initial activity of the radionuclide at the time of packaging. The efficiency of each gamma line was calculated from the specified equation. The detector efficiency calibration was interpreted and the full-energy peak efficiency (FEPE) spectra for all the three geometries using both conventional and semi-empirical approaches were obtained (Gunnink, 1990; Daza et al., 2001).

\section{Standard Y-ray sources}

The standard $\gamma$-ray sources used in this research were as followed ${ }^{241} \mathrm{Am},{ }^{226} \mathrm{Ra},{ }^{152} \mathrm{Eu},{ }^{137} \mathrm{Cs},{ }^{60} \mathrm{Co},{ }^{57} \mathrm{Co},{ }^{54} \mathrm{Mn}$, and ${ }^{22} \mathrm{Na}$. For counting and peak energy calculation, these sources were placed on the sample holder vertically away from the detector at $10 \mathrm{~cm}$ (far geometry) and between 1 to $5 \mathrm{~cm}$ (near-geometry). The full efficiencies were observed at three different region of energies of $200 \mathrm{KeV},(90-200) \mathrm{KeV}$ and (50 -90) $\mathrm{KeV}$. The following expressions were used for calculations (Sadiq et al., 2010, Hall \& Soltys, 1971; Jonah et al., 2005):

$$
\begin{aligned}
& \varepsilon_{p}=\frac{N_{p} / t_{m}}{A_{t} I_{\alpha}} \\
& \varepsilon_{E}=\varepsilon_{O} \exp -A l \cdot \exp \left(\mu_{G e} A_{t}\right) G_{e} \\
& \ln \varepsilon_{E}=A_{1}+A_{3}\left(4.816 \ln E+(\ln E)^{2}\right) \\
& \ln \varepsilon_{E}=\sum_{J=1}^{6} a_{j}(\ln E)^{j-1}
\end{aligned}
$$

Where:

$\boldsymbol{\varepsilon}_{\mathrm{p}}$ is the full energy efficiency,

$\mathrm{N}_{\mathrm{p}}$ is the net area under peak,

$\mathrm{t}_{\mathrm{m}}$ is the live time,

$\mathrm{A}_{\mathrm{t}}$ is the present activity,

$I_{\gamma}$ is the $\gamma$-ray abundance,

$\boldsymbol{\varepsilon}_{\mathrm{E}}$ is the intrinsic efficiency,

$\boldsymbol{\varepsilon}_{\mathrm{o}}$ is ideal efficiency (absolute has no absorption),

$\boldsymbol{\mu}_{\mathrm{EAL}}$ is absorption coefficient for aluminum $\left(\mathrm{cm}^{2} \mathrm{~g}^{-1}\right)$,

$\boldsymbol{\mu}_{\mathrm{EGe}}$ is the absorption coefficient for germanium $\left(\mathrm{cm}^{2} \mathrm{~g}^{-1}\right)$,

$\mathrm{A}_{\mathrm{j}}$ is the constant,

$\mathrm{Al}$ is the thickness of the aluminum $\left(\mathrm{gcm}^{-2}\right)$,

$\mathrm{Ge}$ is the thickness of the germanium $\left(\mathrm{gcm}^{-2}\right)$ 


\section{Sources guide}

${ }^{241} \mathrm{Am}$, is a radioactive element with atomic mass of $241 \mathrm{gmol}^{-1}$, atomic number of 95 and half-life of 141 years. It emits gamma radiation with energies of $60 \mathrm{keV}(36 \%), 18 \mathrm{keV}(18 \%)$, and $14 \mathrm{keV}$ (13\%). The energies of emitted alpha particles are $5486 \mathrm{keV}(85 \%)$, $5443 \mathrm{keV}(13 \%)$ and $5388 \mathrm{keV}(1 \%)$. It has physical half-life of 432.7 years, biological half-life of 50 years (bone) and effective half-life of 45 years (bone). Its melting point, boiling point and density are 1449 $\mathrm{K}, 2880 \mathrm{~K}$ and $13.67 \mathrm{gcm}^{-3}$, respectively. It is diversely used in smoke detector, $\gamma$-radiation sources and medical purposes. ${ }^{226} \mathrm{Ra}$ has atomic mass of $226 \mathrm{gmol}^{-1}$ and atomic number of 88 . This radionuclide source has a long live of half-life and is always encapsulated or sealed because one gram of it can emit or produce 0.2 atmosphere in a free volume of one cubic centimetre per year. Therefore, the natural explosive rapture of this source may occur with accumulation of gasses. Moreover, the safer condition for managing this source is mostly obtained through immobilization of the element. It is used as a neutron source and sometimes combined with beryllium to produce radon for cancer treatment. ${ }^{152} \mathrm{Eu}$ has atomic mass of 152 g.mol ${ }^{-1}$ and an approximate atomic number of 63 , belonging to the lanthanide series and rare earth metals. It readily oxidizes in air and water as well. Europium has almost twenty-one unstable isotopes even though is an excellent neutron absorber.

${ }^{137} \mathrm{Cs}$ has approximate atomic mass of $137 \mathrm{gmol}^{-1}$ and atomic number of 55. In addition, it has the density of $1.9 \mathrm{gcm}^{-1}$ at $20^{\circ} \mathrm{C}$, while the melting and boiling points are $28.4^{\circ} \mathrm{C}$ and $66.9^{\circ} \mathrm{C}$ respectively. It is used in making photoelectric cell, catalyst for hydrogenation, atomic clocks and for marking vacuum tubes. Cesium is so reactive especially when combines with oxygen and violently with water. To prevent it from getting contact with the air or vapor in the laboratory, it has to be stored under mineral oil or kerosene. ${ }^{60} \mathrm{Co}$ has atomic number of 27 and approximate atomic mass of $59 \mathrm{~g} . \mathrm{mol}^{-1}$. it is brittle in nature but belong to ferromagnetic elements that has high melting point of $1.495{ }^{\circ} \mathrm{C}$. Therefore, it has been in use for cutting tool, high-speed steels, and cancer treatment. It is the most important among all the gamma-ray sources used in this research. Due to its nature of spontaneous ignition in air contact, it is classified as highly flammable and it can only be extinguished by dolomite soda ash, sand dry or graphite powder.

${ }^{54} \mathrm{Mn}$ is naturally non-free element often found in iron combination minerals with melting point of $1.246^{\circ} \mathrm{C}$. The manganese can be used as deformation agent of hydrogen in dry cell batteries, decolourizing the glass green colour when having iron contamination, drying agent in black paint, drink cans making, and then resistance improver to corrosion. ${ }^{22} \mathrm{Na}$ is naturally non-free element, though it is the most important alkaline metal, which has atomic mass of $22.989769 \mathrm{u} \pm$ $2 \times 10^{-8} \mathrm{u}$ and atomic number of 11 . It is sixth most abundant element in the earth crust products and it is very reactive with low melting point and relative density of 0.97 at $20^{\circ} \mathrm{C}$. It is used for refining some metals, improving alloy structures, desiccant for drying solvents, organic reducing agent for chemical industry feed stock, common salt, de-icing roads during winter period and soda making (Jonah et al., 2005; Jonah et al., 2007; Abubakar et al., 2017).

\section{Miniature neutron source reactor (MNSR)}

The MNSR is a small and compacted China made reactor, which is modelled based on high enrichment uranium (NEU) slowpoke-2, the Canadian design. The general technical specifications of the reactor were presented in Table 1. Fig. 1, 2 and 3 illustrate the schematic diagram, sectional view and layout core configuration of the reactor, respectively.
Table 1 Technical Specifications of NIRR-1.

\begin{tabular}{ll}
\hline Parameters & Description \\
\hline Reactor type & Tank-in-pool \\
Rated thermal power & $30 \mathrm{Kw}$ \\
Fuel & UAl4l \\
U-234 Enrichment & $90.2 \%$ \\
Core shape & Cylinder \\
Core diameter & $23.0 \mathrm{~cm}$ \\
Core height & $23.0 \mathrm{~cm}$ \\
No. of fuel elements & 347 \\
Weight of U-235 & $999.36 \mathrm{~g}$ \\
Total number of irradiation sites & 10 \\
Inner channels & 5 \\
Flux in inner channel & $1-10^{12} \mathrm{n} \mathrm{cm}^{-2} \mathrm{~s}^{-1}$ \\
Flux in outer channel & $5-10^{11} \mathrm{n} \mathrm{cm}^{-2} \mathrm{~s}^{-1}$ \\
Reactor cooling mode & $\mathrm{Natural} \mathrm{convection}$ \\
Eight of inlet orifice & $6 \mathrm{~mm}$ \\
Height of outlet orifice & $7.5 \mathrm{~mm}$ \\
Diameter of fuel meat & $4.3 \mathrm{~mm}$ \\
Diameter of fuel element & $5.50 \mathrm{~mm}$ \\
Excess reactivity & $3.77 \mathrm{mk}$ \\
Length of Cd control rod & $230 \mathrm{~mm}$ \\
\hline
\end{tabular}

(Jonah et al., 2005; Ahmed et al., 2006; Sadiq et al., 2010: Musa, Y. et al., 2012).

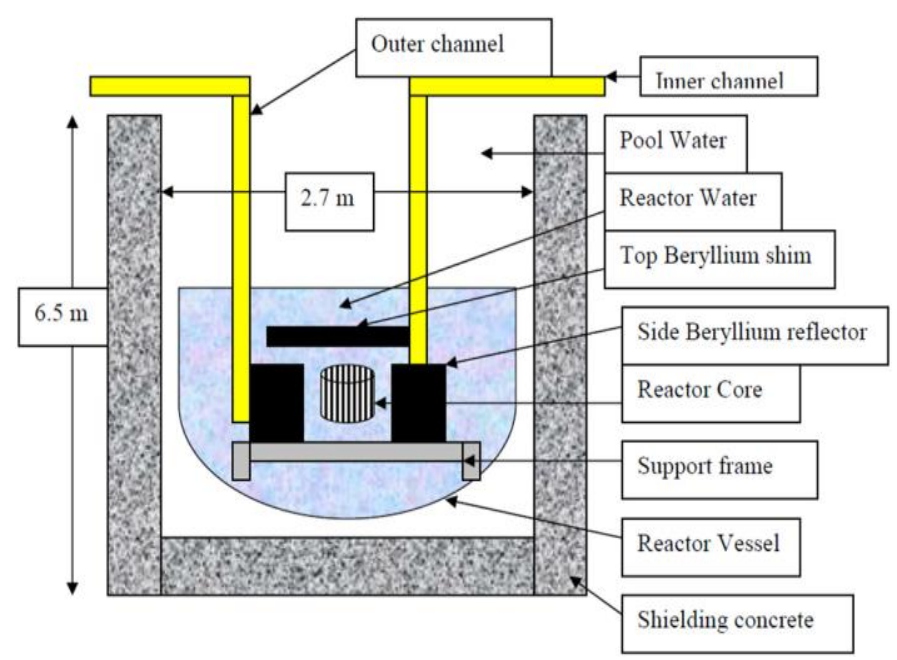

Fig. 1 Schematic diagram of MNSR (NIRR-1).

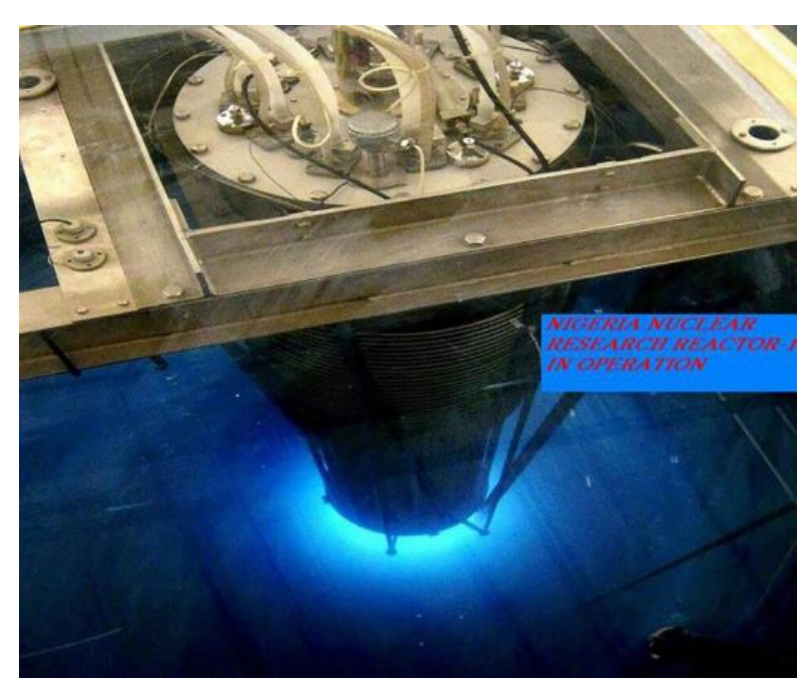

Fig. 2 Cross-sectional view of NIRR-1. 


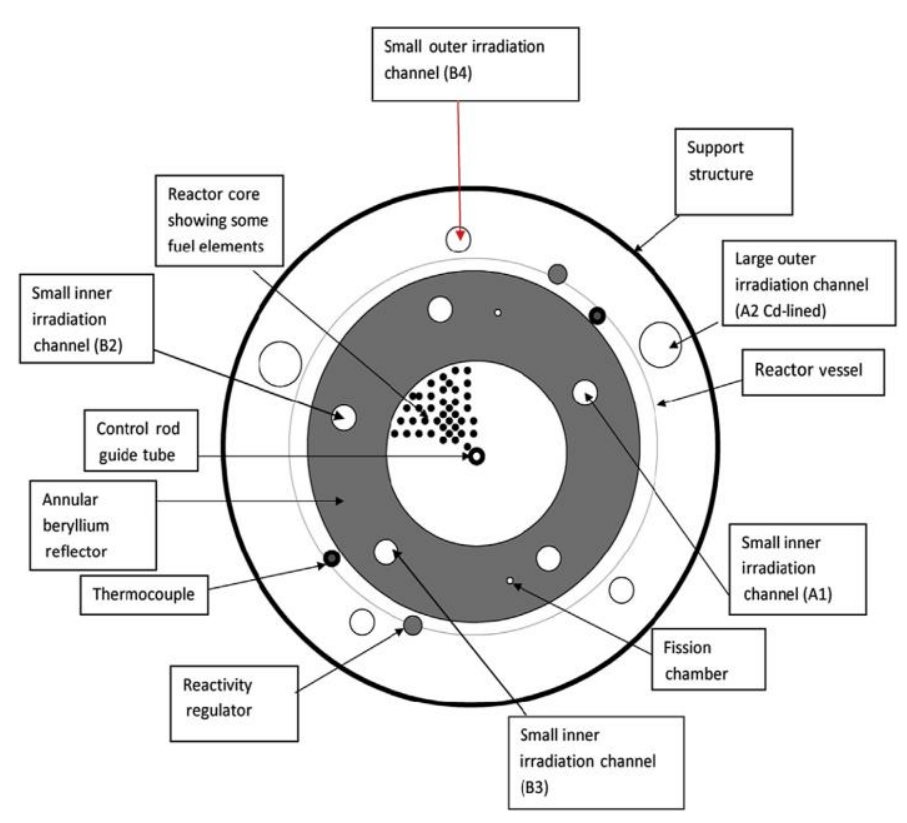

Fig. 3 A layout NIRR-1 core configuration showing various components (Ahmed et al., 2006: Abubakar et al., 2017: Yahaya et al., 2017).

\section{RESULTS AND DISCUSSION}

Semi Empirical Approach with Three Geometries (10, 5 and $1 \mathrm{~cm})$

Table 2 presents a semi-empirical information of the energies and their corresponding calculated efficiencies from all the three chosen geometries in this research. The results were used in plotting spectra that presented in Fig. 7 -9 below.

\section{Conventional Approach with Three Geometries}

Table 3 presents a conventional information for energies and their corresponding efficiencies from all the three chosen geometries in this research. The presented results in Fig. $4-6$ were used in plotting the spectra observed during the analysis.

\section{Description of the figures}

Generally, by close observation of the entire efficiency curves demonstrated in Fig. 5 to 9 , it descrived how the efficiency at low energy was gradually increased. The gradual increased in the efficiency was inturned attributed to the high gamma ray abundance of the sources. Then, there was a decline in the spectra with an exponential increase in energy and decrease in efficiencies until it reached the alpha emission boundary. At most, the highest full energy peak efficiencies of all the spectra were observed to be within the energy range of 0.2 to $0.26 \mathrm{KeV}$, which were independent of the geometry, hence following the statistical probability approximation.

In the case of conventional approaches, the corresponding chemical element found at the highest efficiency was radium ${ }^{226} \mathrm{Ra}$, which proved the tendency of having other elements with multiple isotopes when the calibration curve was extended to energies above $4 \mathrm{MeV}$. Therefore, it was a leading key to the semi empirical approach (Jonah, Balogun et al., 2005, Jonah, Ibikunle et al., 2009).

Similarly, in the case of semi empirical approaches, the three geometries were observed to have their highest full energy peaks efficiency at almost around same peak position, irrespective of the geometry. Even though, in semi empirical approach there was a good agreement in the spectrum of 10 and $5 \mathrm{~cm}$ geometries, whereas for conventional, 1 and $5 \mathrm{~cm}$ geometries were more consistent, as referred to Fig. $4-9$.

Furthermore, the respective efficiencies for the three geometries of $1 \mathrm{~cm}, 5 \mathrm{~cm}$ and $10 \mathrm{~cm}$ were presented in Table 4 (Salawu and Balogun, 2017). However, some distinct deviations from the linear calibration curve were observed in region III which accounted by the accurate efficiency curves that was analytically described before. This nonlinearity or distinct deviation of the efficiency curve was directly attributed to the higher order coefficient terms that were related to the volume of the high purity germanium detector used in this research (Storm and Israel, 1970, Abubakar, et al. 2017).

The calibration of the vertical dipstick HPGe was recommended earlier to serve as an alternative to that horizontal detector. This replacement might eventually increase the precision and efficiency of both detectors, thereby it was expected to improve the NAA and large sample NAA per day. Simultaneously, it would reduce considerably the delay of a long queuing and over dependence on a single detector, eventhough the resolution of the installed HPGe detector was not yet satisfactory. Thus, it was necessary to install n-type HPGe detector with an operating energy range of 0.1 to $10 \mathrm{MeV}$ for better resolution and high full energy efficiency. This type of detector was certainly suitable for large scale analysis of different nuclear structures having high $\gamma$-ray multiplicities or in an array form (Bode et al., 1990; Greenberg et al., 2011; Iliyasu et al., 2017)

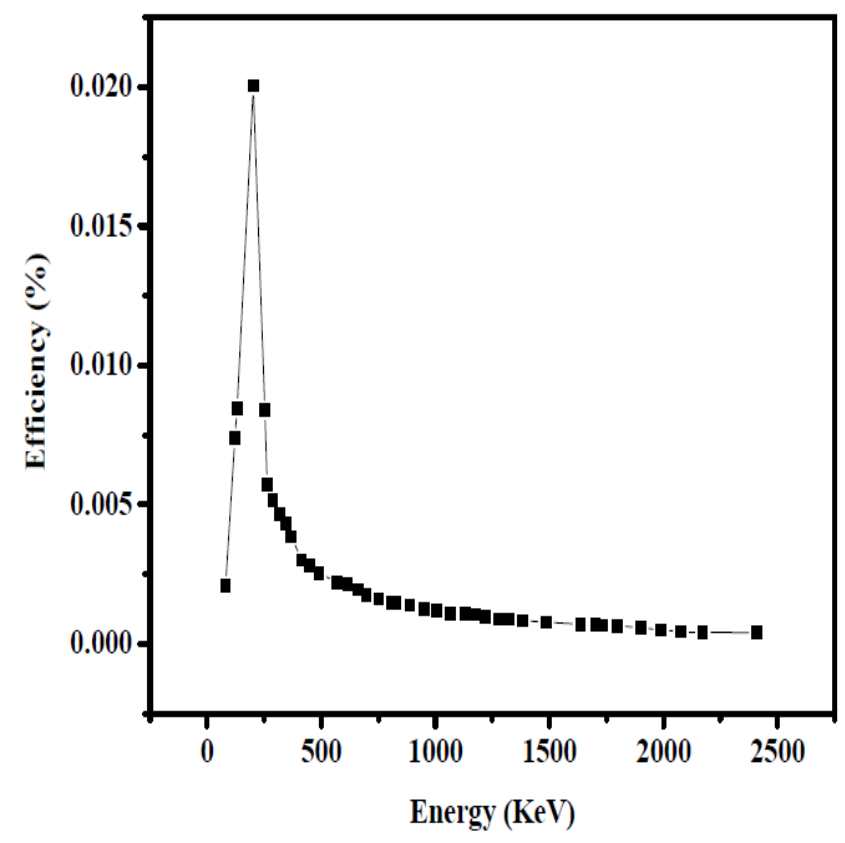

Fig. 4 Energy dependent efficiency for $1 \mathrm{~cm}$ distance using conventional approach.

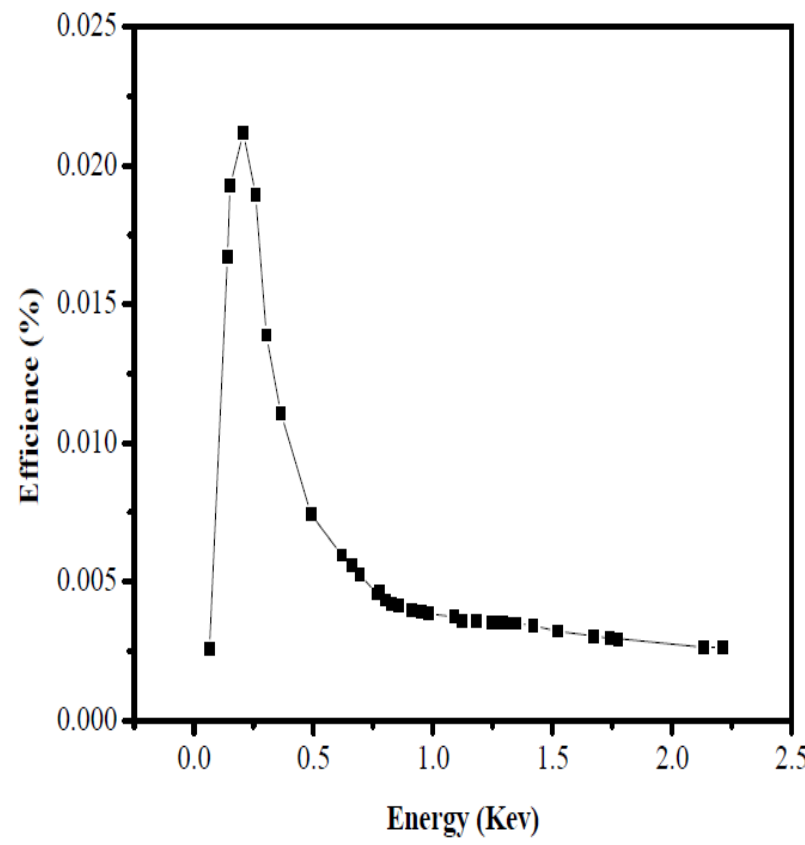

Fig. 5 Energy dependent efficiency for $5 \mathrm{~cm}$ distance using conventional approach. 


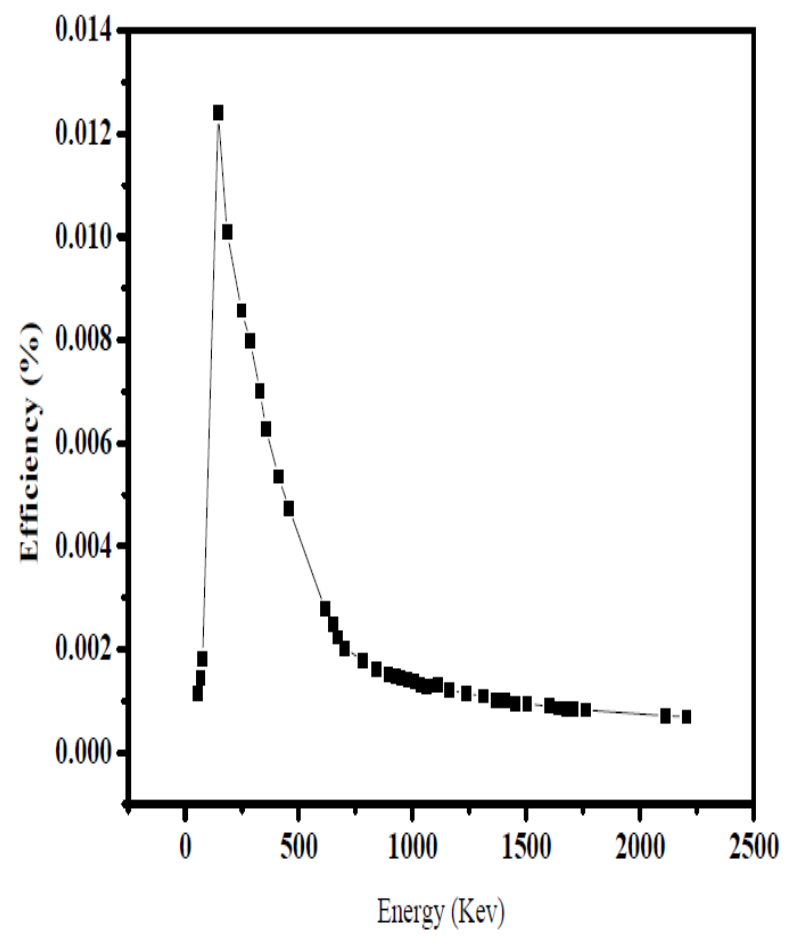

Fig. 6 Energy dependent efficiency for $10 \mathrm{~cm}$ distance using conventional approach.

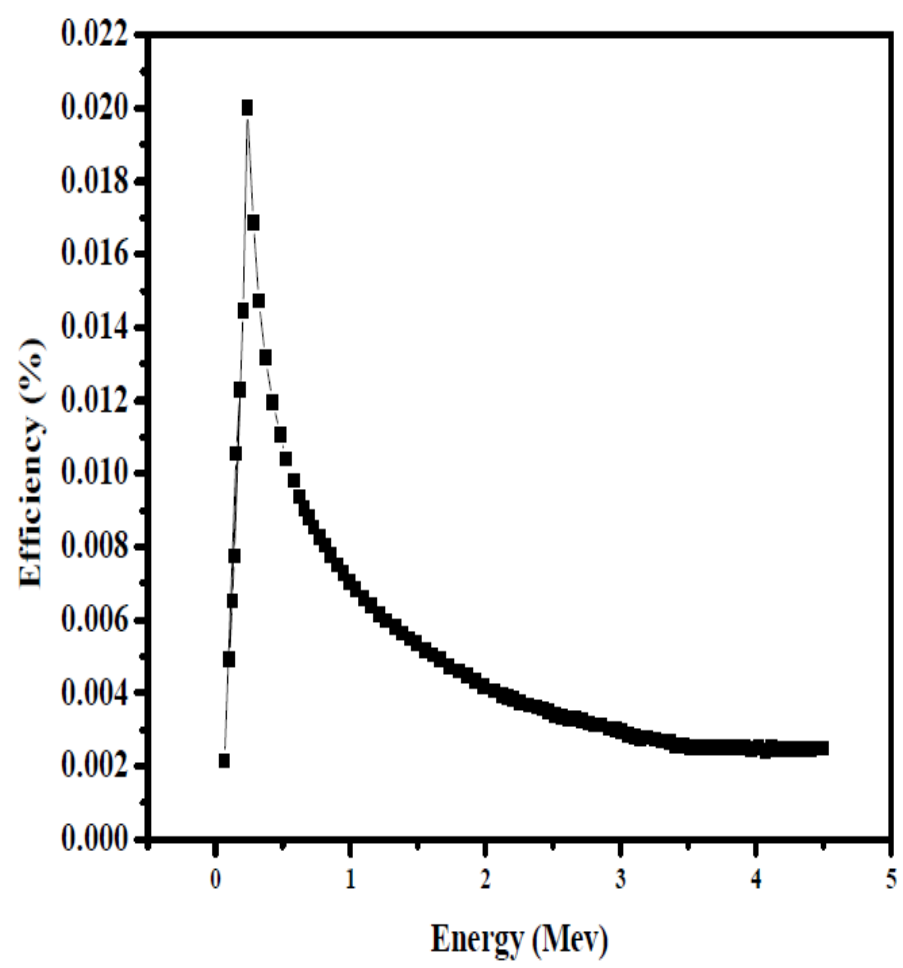

Fig. 7 Energy dependent efficiency for $1 \mathrm{~cm}$ distance using semiempirical approach.

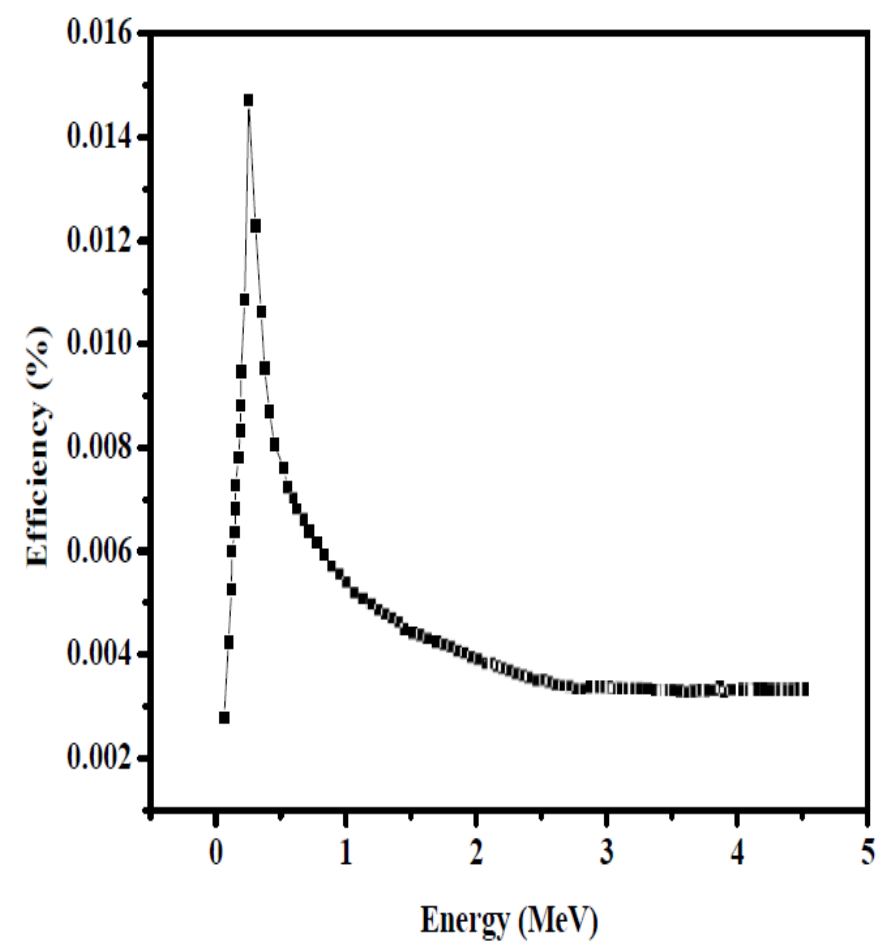

Fig. 8 Energy dependent efficiency for $5 \mathrm{~cm}$ distance using semiempirical approach.

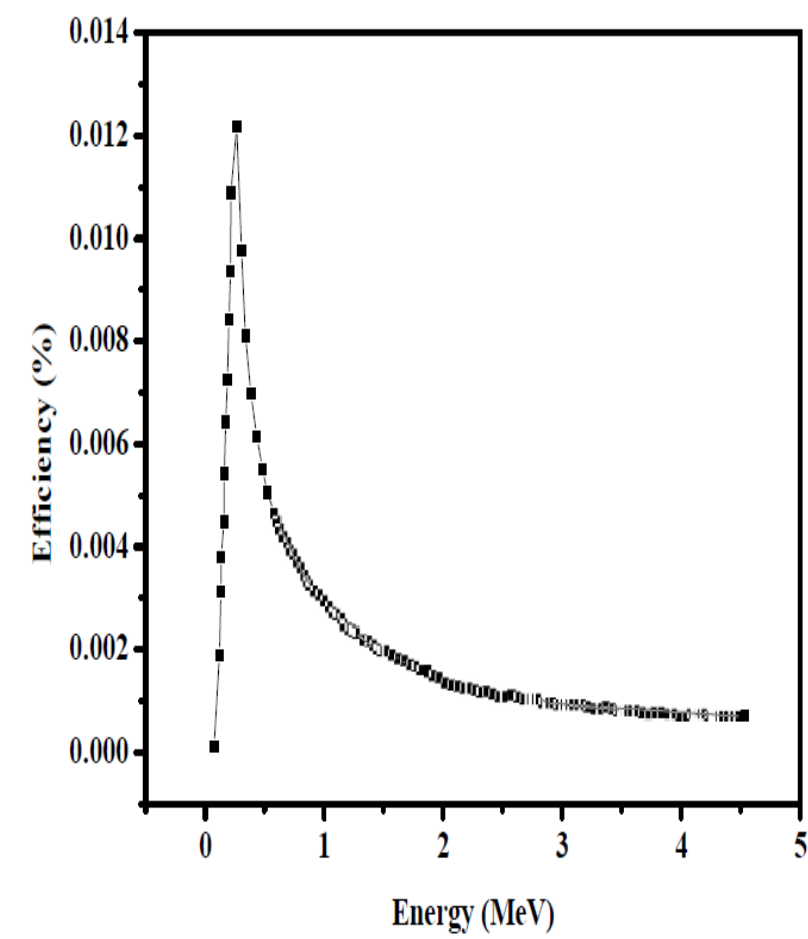

Fig. 9 Energy dependent efficiency for $10 \mathrm{~cm}$ distance using semiempirical approach. 
Table 2 Distance dependent results obtained using semi-empirical approach.

\begin{tabular}{|c|c|c|c|c|c|}
\hline $10 \mathrm{~cm}$ & & $5 \mathrm{~cm}$ & & $1 \mathrm{~cm}$ & \\
\hline Efficiency (\%) & Energy (MeV) & $\begin{array}{c}\text { Efficiency } \\
(\%)\end{array}$ & Energy (MeV) & $\begin{array}{c}\text { Efficiency } \\
(\%)\end{array}$ & $\begin{array}{c}\text { Energy } \\
(\mathrm{MeV})\end{array}$ \\
\hline 1.13208E-4 & 0.07428 & 0.00279 & 0.06454 & 0.00214 & 0.06735 \\
\hline 0.0019 & 0.11858 & 0.00424 & 0.0978 & 0.01055 & 0.15403 \\
\hline 0.00312 & 0.13203 & 0.00526 & 0.12103 & 0.01228 & 0.18337 \\
\hline 0.00381 & 0.13325 & 0.00599 & 0.12351 & 0.00493 & 0.10269 \\
\hline 0.00449 & 0.1577 & 0.00637 & 0.14654 & 0.00652 & 0.12469 \\
\hline 0.00542 & 0.15892 & 0.00682 & 0.14893 & 0.00775 & 0.13936 \\
\hline 0.00643 & 0.17237 & 0.00728 & 0.15131 & 0.01447 & 0.20538 \\
\hline 0.00725 & 0.18582 & 0.0078 & 0.17514 & 0.02 & 0.23571 \\
\hline 0.00842 & 0.19927 & 0.00833 & 0.18844 & 0.01688 & 0.28125 \\
\hline 0.00936 & 0.21271 & 0.00882 & 0.19102 & 0.01473 & 0.32105 \\
\hline 0.01088 & 0.21516 & 0.00946 & 0.1944 & 0.01317 & 0.36881 \\
\hline 0.01219 & 0.26415 & 0.01086 & 0.2228 & 0.01196 & 0.42423 \\
\hline 0.00977 & 0.30407 & 0.01471 & 0.25357 & 0.01107 & 0.4801 \\
\hline 0.00811 & 0.33744 & 0.01229 & 0.30401 & 0.0104 & 0.522 \\
\hline 0.00698 & 0.38411 & 0.01063 & 0.3479 & 0.00982 & 0.57832 \\
\hline 0.00615 & 0.43237 & 0.00953 & 0.37371 & 0.00906 & 0.6558 \\
\hline 0.00551 & 0.48163 & 0.0087 & 0.41144 & 0.00937 & 0.62054 \\
\hline 0.00506 & 0.52135 & 0.00806 & 0.45016 & 0.00879 & 0.69114 \\
\hline 0.00464 & 0.58232 & 0.0076 & 0.52145 & 0.00853 & 0.72647 \\
\hline 0.00434 & 0.62284 & 0.00722 & 0.55103 & 0.00826 & 0.76894 \\
\hline 0.00408 & 0.68461 & 0.00703 & 0.59214 & 0.00804 & 0.81148 \\
\hline 0.00385 & 0.73605 & 0.00681 & 0.62252 & 0.00777 & 0.85395 \\
\hline 0.00358 & 0.79782 & 0.00662 & 0.67415 & 0.0075 & 0.90357 \\
\hline 0.00325 & 0.86971 & 0.00639 & 0.71505 & 0.00728 & 0.94611 \\
\hline 0.00343 & 0.8286 & 0.00616 & 0.77701 & 0.00705 & 0.98865 \\
\hline 0.00332 & 0.84906 & 0.00593 & 0.82844 & 0.00683 & 1.03833 \\
\hline 0.0037 & 0.76683 & 0.0057 & 0.89039 & 0.00661 & 1.09515 \\
\hline 0.00449 & 0.60258 & 0.00555 & 0.95274 & 0.00638 & 1.15198 \\
\hline 0.00419 & 0.65362 & 0.0054 & 1.00457 & 0.00616 & 1.2088 \\
\hline
\end{tabular}


Umar et al. / Malaysian Journal of Fundamental and Applied Sciences Vol. 15, No. 2 (2019) 282-290

\begin{tabular}{|l|l|l|l|l|l|}
\hline 0.00392 & 0.70487 & 0.00519 & 1.06724 & 0.00598 & 1.26569 \\
\hline 0.00313 & 0.91122 & 0.00507 & 1.12958 & 0.0058 & 1.32972 \\
\hline 0.00306 & 0.95293 & 0.00497 & 1.19182 & 0.00562 & 1.37946 \\
\hline 0.00294 & 0.99444 & 0.00486 & 1.24384 & 0.00549 & 1.43642 \\
\hline 0.00283 & 1.03595 & 0.00478 & 1.29607 & 0.00536 & 1.48622 \\
\hline 0.00268 & 1.09831 & 0.0047 & 1.34829 & 0.00518 & 1.55026 \\
\hline 0.00249 & 1.16048 & 0.00463 & 1.40052 & 0.00504 & 1.60721 \\
\hline 0.00272 & 1.06693 & 0.0045 & 1.44254 & 0.00491 & 1.66416 \\
\hline 0.0026 & 1.14002 & 0.00443 & 1.51529 & 0.00473 & 1.72819 \\
\hline 0.00242 & 1.20218 & 0.00439 & 1.56771 & 0.0046 & 1.79943 \\
\hline 0.00234 & 1.26495 & 0.00432 & 1.61994 & 0.00446 & 1.86352 \\
\hline
\end{tabular}

Table 3 Distance dependent results obtained using conventional approach.

\begin{tabular}{|c|c|c|c|c|c|}
\hline $10 \mathrm{~cm}$ & & $5 \mathrm{~cm}$ & & $1 \mathrm{~cm}$ & \\
\hline $\begin{array}{c}\text { Efficiency } \\
(\%)\end{array}$ & $\begin{array}{c}\text { Energy } \\
(\mathrm{KeV})\end{array}$ & $\begin{array}{c}\text { Efficiency } \\
(\%)\end{array}$ & Energy (KeV) & $\begin{array}{c}\text { Efficiency } \\
(\%)\end{array}$ & $\begin{array}{c}\text { Energy } \\
(\mathrm{KeV})\end{array}$ \\
\hline 0.00113 & 55.55556 & 0.00257 & 0.0647 & 0.00208 & 80.80808 \\
\hline 0.00144 & 68.45966 & 0.01671 & 0.1399 & 0.00739 & 121.2121 \\
\hline 0.00182 & 76.92308 & 0.01928 & 0.1511 & 0.00847 & 131.3131 \\
\hline 0.0124 & 145.29915 & 0.02118 & 0.2064 & 0.02004 & 202.0202 \\
\hline 0.01009 & 183.76068 & 0.01895 & 0.2579 & 0.00839 & 252.5252 \\
\hline 0.00857 & 247.86325 & 0.01388 & 0.3025 & 0.00573 & 262.6262 \\
\hline 0.00798 & 286.32479 & 0.01106 & 0.3636 & 0.00516 & 287.8787 \\
\hline 0.00701 & 329.05983 & 0.00744 & 0.4896 & 0.00465 & 318.1818 \\
\hline 0.00629 & 354.70085 & 0.00595 & 0.6179 & 0.00433 & 343.4343 \\
\hline 0.00535 & 410.25641 & 0.0056 & 0.6625 & 0.00385 & 368.8041 \\
\hline 0.00473 & 457.26496 & 0.00527 & 0.6931 & 0.00301 & 414.1475 \\
\hline 0.00279 & 615.38462 & 0.00457 & 0.7640 & 0.00279 & 449.4949 \\
\hline 0.00249 & 649.7555 & 0.00465 & 0.7775 & 0.00254 & 489.8989 \\
\hline 0.00223 & 670.94017 & 0.00433 & 0.8001 & 0.00221 & 570.7070 \\
\hline 0.00202 & 700.8547 & 0.00419 & 0.8264 & 0.00214 & 616.1616 \\
\hline 0.00179 & 781.78484 & 0.00413 & 0.8575 & 0.00194 & 661.6161 \\
\hline 0.00162 & 841.68704 & 0.00397 & 0.9113 & 0.00175 & 696.9697 \\
\hline 0.00151 & 893.03178 & 0.00393 & 0.9511 & 0.00162 & 752.5252 \\
\hline 0.00148 & 927.26161 & 0.00384 & 0.9822 & 0.00148 & 808.0808 \\
\hline
\end{tabular}




\begin{tabular}{|c|c|c|c|c|c|}
\hline 0.00144 & 948.65526 & 0.00373 & 1.0892 & 0.00148 & 828.2828 \\
\hline 0.00141 & 978.60636 & 0.00358 & 1.12042 & 0.00138 & 888.91976 \\
\hline 0.00137 & 1008.55746 & 0.00356 & 1.1827 & 0.00125 & 949.5999 \\
\hline 0.00132 & 1034.2298 & 0.00354 & 1.2451 & 0.0012 & 1005.050 \\
\hline 0.00128 & 1059.9022 & 0.00354 & 1.2897 & 0.00107 & 1065.656 \\
\hline 0.0013 & 1085.5745 & 0.0035 & 1.3160 & 0.00106 & 1131.313 \\
\hline 0.00131 & 1111.2469 & 0.0035 & 1.3478 & 0.00106 & 1176.767 \\
\hline 0.00121 & 1162.5916 & 0.00341 & 1.4187 & $9.602 \mathrm{E}-4$ & 1216.992 \\
\hline 0.00115 & 1235.3300 & 0.00321 & 1.5213 & $8.920 \mathrm{E}-4$ & 1277.672 \\
\hline 0.00109 & 1311.7359 & 0.00304 & 1.6729 & $8.852 \mathrm{E}-4$ & 1323.016 \\
\hline 0.00102 & 1367.3594 & 0.00291 & 1.7750 & $8.404 \mathrm{E}-4$ & 1383.838 \\
\hline 0.001 & 1405.8679 & 0.00298 & 1.7396 & $7.760 \mathrm{E}-4$ & 1485.052 \\
\hline $9.451 \mathrm{E}-4$ & 1452.9339 & 0.00263 & 2.1318 & 7.077E-4 & 1636.419 \\
\hline $9.410 \mathrm{E}-4$ & 1504.2787 & 0.00263 & 2.2121 & $6.731 \mathrm{E}-4$ & 1702.020 \\
\hline $9.008 \mathrm{E}-4$ & 1602.6894 & 0.00263 & 2.1318 & $6.693 \mathrm{E}-4$ & 1732.323 \\
\hline 8.632E-4 & 1641.1980 & 0.00263 & 2.2121 & $6.463 \mathrm{E}-4$ & 1797.788 \\
\hline
\end{tabular}

Table 4 Geometry dependent calibration results.

\begin{tabular}{ccccc}
\hline Geometry & \multicolumn{2}{c}{$\begin{array}{c}\text { Semi-empirical } \\
\text { approach }\end{array}$} & \multicolumn{2}{c}{$\begin{array}{c}\text { Conventional- } \\
\text { approach }\end{array}$} \\
\hline $\begin{array}{c}\text { Far/ } \\
\text { Closed }\end{array}$ & $\begin{array}{c}\text { Energy } \\
(\mathrm{MeV})\end{array}$ & $\begin{array}{c}\text { Efficiency } \\
(\%)\end{array}$ & $\begin{array}{c}\text { Energy } \\
(\mathrm{MeV})\end{array}$ & $\begin{array}{c}\text { Efficien } \\
\text { cy }(\%)\end{array}$ \\
\hline $10 \mathrm{~cm}$ (far) & 0.26415094 & 0.012188679 & 145.2991453 & $\begin{array}{c}0.0124 \\
03772\end{array}$ \\
& & & & 0.0211 \\
$5 \mathrm{~cm}$ & 0.25357426 & 0.01217911 & 0.206414474 & 84211 \\
$\begin{array}{c}\text { (closed) } \\
1 \mathrm{~cm}\end{array}$ & 0.23571428 & 0.02 & 202.020202 & 0.0200 \\
(closed) & & & & 40276
\end{tabular}

\section{CONCLUSIONS}

We were successfully calibrated both the energy and efficiency of the HPGe detector for use in NAA in NIRR-1 reactor, while using MAESTRO software for spectral and data acquisition. The efficiency of being a basic parameter of detector was found to be independent of the source to detector geometry. The semi-empirical and conventional approaches were generalized to evaluate the coincidence-summing corrections associated with cascade $\gamma$-rays emission. The full energy peaks efficiency was significant compared the relative, absolute and intrinsic efficiency. The efficiency of the vertical dipstick HPGe detector was discerned to be proportional to the activity of the standard $\gamma$-ray sources and the number of counts. Besides that, the photons detected by the vertical dipstick ORTEC HPGe coaxial detector revealed the highest efficiency in certain energy range. Irrespective of the geometry, the FEPE was increased at a particular point at lower energy region until it attained the optimum value. Thereafter, it followed an exponential decay at higher energies. The physical and environmental factors that generally affected the detector's efficiency could be avoided through constant counting during the calibration process. The uncertainties of the efficiency calibration were depended on the number of data employed during the experiment. The conventional and semi-empirical approaches have enhanced the reliability in determining the environmental sample activities over the desired energy ranges and even above $2000 \mathrm{KeV}$. Hence, present calibration approaches were affirmed to be efficient and capable of producing accurate and precise results, especially at low energies.

\section{ACKNOWLEDGEMENTS}

The authors are grateful to the CERT, ABU, Zaria, Nigeria for permitting to access the facilities and the technical staff for their kind gesture and coorperate. Thanks are due to Universiti Teknologi Malaysia (UTM), Malaysia for providing good electronic facilities, internet accessibility and the financial support (University Research Grant).

\section{REFERENCES}

Abubakar, A. U., Hamzah, K., Sadiq, U., Jonah, S. A. (2017). Slant tube characterization for the implementation of $\mathrm{k} 0$-standardization in Nigerian reseach reactor-1. Malaysian Journal of Fundamental and Applied Sciences, 13(2), 95-99.

Ahmed, Y., Ewa, I. O. B., Umar, M., Bezbornah, T., Johri, M., Akaho, E. H. K. (2006). The low power miniature neutron source reactors: design, safety and applications. Nigerian Journal of Physics, 14(1), 82-85.

Akaho, E.H. K., Nyarko, B. J. B. (2002). Characterization of neutron flux spectra in irradiation sites of MNSR reactor using the Westcott-formalism for the $\mathrm{k}_{0}$ neutron activation analysis method. Applied Radiation and Isotopes, 57 (2), 265-273.

Alghem, L., Ramdhane, M., Khaled, S., Akhal, T. (2006). The development and application of $\mathrm{k} 0$-standardization method of neutron activation analysis at Es-Salam research reactor. Nuclear Instruments and Methods in Physics Research Section A: Accelerators, Spectrometers, Detectors and Associated Equipment, 556(1), 386-390.

Bode, P., Hoffman, E. L., Lindstrom, R. L., Parry, S. J. (1990). Practical aspects of operating a neutron activation analysis laboratory. IAEA Techdoc, 564. 
Daza, M. J., Quintana, B., Garcia-Talavera, M., Fernandez, F. (2001). Efficiency calibration of a HPGe detector in the [46.54-2000] keV energy range for the measurement of environmental samples. Nuclear Instruments and Methods in Physics Research Section A: Accelerators, Spectrometers, Detectors and Associated Equipment, 470(3), 520-532.

De Cortea, F., Sluijs, R.V., Simonits, A., Kucera, J., Smodis, B., Byrnee, A.R., De Wispelaerea, A., Bossus, D., Frana, J., Horak, Z., Jacimovi, R. (2001) Installation and calibration of Kayzero-assisted NAA in three Central European countries via a Copernicus project. Applied Radiation and Isotopes, 55(3), 347-354.

Greenberg, R. R., Bode, P., De Nadai Fernandes, E. A. (2011). Neutron activation analysis: A primary method of measurement. Spectrochimica Acta Part B Atomic Spectroscopy, 66(3), 193-241.

Gunnink, R. (1990). New method for calibrating a Ge detector by using only zero to four efficiency points. Nuclear Instruments and Methods in Physics Research Section A: Accelerators, Spectrometers, Detectors and Associated Equipment, 299(1-3), 372-376.

Hall, R., Soltys, T. (1971). High purity germanium for detector fabrication. IEEE Transactions on Nuclear Science, 18(1), 160-165.

Hamidatou, L., Slamene, H., Akhal, T., Begaa, S., Messaoudi, M., Boussaad, Z. (2013). NAA Algerian Laboratory Evaluation Processed by WEPAL and IAEA during 2011-2012. Journal of Analytical Sciences, Methods and Instrumentation, 3(04), 184-192.

Hamidatou, L., Slamene, H., Mohamed L. S. (2015). Major, minor and trace elements in four kinds of cement powder using INAA and k0-standardization methods. Journal of Radioanalytical and Nuclear Chemistry, 304(2), 717725.

Iliyasu, U., Ibrahim, Y. V., Umar, S., Agbo, S. A., Jibrin, Y. (2017). An investigation of reactivity effect due to inadvertent filling of the irradiation channels with water in NIRR-1 Nigeria Research Reactor-1. Applied Radiation and Isotopes, 123, 11-16.

Jonah, S.A., Balogun, G.I., Umar, M.I., Mayaki, M.C. (2005). Neutron spectrum parameters in irradiation channels of the Nigeria Research Reactor-1 (NIRR1) for the $\mathrm{k}_{0}$-NAA standardization. Journal of Radioanalytical and Nuclear Chemistry, 266(1), 83-88.
Jonah, S. A., Liaw, J. R., Matos J. E. (2007). Monte Carlo simulation of core physics parameters of the Nigeria Research Reactor-1 (NIRR-1). Annals of Nuclear Energy, 34(12), 953-957.

Jonah, S. A., Ibikunle, K., Li, Y. (2009). A feasibility study of LEU enrichment uranium fuels for MNSR conversion using MCNP. Annals of Nuclear Energy, 36(8), 1285-1286.

Khandaker, M. U. (2011). High purity germanium detector in gamma-ray spectrometry. International Journal of Fundamental Physical Sciences, 1 (2), 42-46.

Musa, Y., Ahmed, Y. A., Yamusa, Y. A., Ewa, I. O. B. (2012). Determination of radial and axial neutron flux distribution in irradiation channel of NIRR-1 using foil activation technique. Annals of Nuclear Energy, 50, 50 - 55.

Musa,Y., Ahmed, Y. A., Yamusa, Y. A., Tukur, M. (2014). Neutron flux variation at the inner irradiation channel of the Nigeria Research Reactor-1 (NIRR-1). Journal of Technology Innovations in Renewable Energy (LifeScience Global), 3(4), 171 - 176.

Sadiq, U., Jonah, S. A., Nasiru, R., Zakari, Y. I. (2010). Neutron spectrum parameters in two irradiation channels of the Nigeria research reactor-1 (nirr1) for use in $\mathrm{k}_{0}$-NAA. Bayero Journal of Pure and Applied Sciences, 3(1), 57-63.

Salawu, A., Balogun, G. I. (2017). Prediction of Peak temperatures of nigeria research reactor core components under several reactivity accident tests. FUOYE Journal of Engineering and Technology 2(1), 86-90.

Storm, L., Israel, H. I. (1970). Photon cross sections from $1 \mathrm{keV}$ to $100 \mathrm{MeV}$ for elements $\mathrm{Z}=1$ to $\mathrm{Z}=100$. Atomic Data and Nuclear Data Tables 7(6), 565681.

Vermaerckea, P., Robouchb, P., Eguskizab, M., De Cortec, F., Kennedyd, G., Smodis, B., Jac'imovic, R., Yonezawaf, C., Matsuef, H., Ling, X., Blaauwh, M., Kucera, J. (2006). Characterisation of synthetic multi-element standards (SMELS) used for the validation of $\mathrm{k}_{0}$-NAA. Nuclear Instruments and Methods in Physics Research Section A: Accelerators, Spectrometers, Detectors and Associated Equipment, 564(2), 675-682.

Yahaya, B., Ahmed, Y. A., Balogun, G. I., Agbo, S. A. (2017). Estimating NIRR1 burn-up and core life time expectancy using the codes WIMS and CITATION. Results in Physics, 7, 596-603. 